\title{
MODELLING OF NITROGEN OXIDES FORMATION APPLYING DIMENSIONAL ANALYSIS
}

\author{
Mária Čarnogurská ${ }^{*}$, Miroslav Př́íhoda ${ }^{2}$, Tomáš Brestovič ${ }^{1}$ \\ ${ }^{1}$ Technical University of Košice, Faculty of Mechanical Engineering, Department of Power \\ Engineering, Vysokoškolská 4, 04200 Košice, Slovakia \\ ${ }^{2}$ VŠB - Technical University of Ostrava, Faculty of Metallurgy and Materials Engineering, \\ Department of Thermal Engineering, 17. listopadu 15, 70833 Ostrava-Poruba, Czech Republic
}

\begin{abstract}
The article presents the procedure for how to establish a mathematical model of nitrogen oxides formation based on the theory of dimensional analysis. The model is based on selected physical quantities (parameters) measurable during regular operation of a heat generation plant. The objective of using dimensional analysis to describe nitrogen oxides formation is to show that between operating parameters of the combustion equipment and the $N O_{x}$ formation there is a significant correlation. The obtained results, which are further described in this article, have proved this fact.
\end{abstract}

The obtained formula expressing nitrogen oxides formation, based on dimensional analysis, applies universally to any boiler fuelled by coal, gas or biomass. However, it is necessary to find $C, m, n$ constants for the formula by experiment, individually for each type of boiler and used fuel. The experiment is based on on-line measurements of selected operational parameters for a given boiler, combusting a certain type of fuel with its actual moisture content and calorific value. The methodology, described in this article, helps to find relationships between the operational parameters and the formation of $N O_{x}$ emissions for a particular furnace. The developed mathematical model has been validated with boilers fuelled by black coal and biomass. Both the results obtained from direct measurements of $N O_{x}$ in both types of boilers, and the results obtained by calculation using equation based on the dimensional analysis, are in a very good accord. When burning coal, the variation between $N O_{x}$ expression from the model and the on-line measurements ranges between $-12.23 \%$ and $+9.92 \%$, and for burning biomass between $-0.54 \%$ and $0.48 \%$.

The intention of the authors is to inform the professional community about the suitability of the dimensional analysis to describe any phenomena for which there is currently no exact mathematical formulation based on differential equations or empirical formulas. Many other examples of dimensional analysis applications in practice may be found in the work of Čarnogurská and Př́ihoda (2011).

Keywords: nitrogen oxides, dimensional analysis, mathematical modelling

\section{INTRODUCTION}

It is generally known that nitrogen oxides formation in exhaust gases is rather complicated, and until now the process has not been precisely described due to all factors accompanying and affecting this process. Among the main factors having a significant impact on the formation of nitrogen oxides are (Horbaj, 1999; Jandačka and Malcho, 2007; Rédr and Př́hoda, 1991):

- excessive volume of the combustion air flow,

- recirculation of exhaust gases, 
- multiple inlets of the combustion air,

- flame temperature,

- design of burners.

A significant factor affecting the formation of nitrogen oxides is the combustion temperature. Except for this factor, the attention has also been paid in the mentioned works to other factors that clearly affect $N O_{x}$ production.

A review of nitrogen oxides formation models since Zeldovič's model of the thermal $N O_{x}$ formation was established (Zeldovič, 1947) until 1997 may be found in the work of Muzio and Quartucy (1997). The effect of mainly chemical additives on nitrogen oxides formation is analyzed throughout the course of combustion process. The effect of combustion temperatures ranging from $1000{ }^{\circ} \mathrm{C}$ to $1600{ }^{\circ} \mathrm{C}$ in combustion of four selected types of China's coal on the production of thermal nitrogen oxides and their total volume is analyzed in the work of Fan et al. (2010). It was found that higher $N O_{x}$ emissions are produced at lower $\left(1000{ }^{\circ} \mathrm{C}\right)$ and high temperatures $\left(1600^{\circ} \mathrm{C}\right)$. As empirical practice shows the production of nitrogen oxides also proportionally depends on nitrogen content in fuel. The effect of combustion air high temperatures on the production of nitrogen oxides in the combustion of fluid coal with a large excess of combustion air is addressed in the work of Zhu et al. (2009). The results of their work showed that the increasing retention time of fluid coal in the reducing zone results in drop of the nitrogen oxides level. During their experiments they also observed an increase in the amount of nitrogen oxides which coincided with an increase of combustion air, combustion temperature, greater granularity of coal and higher concentration of oxygen. The results of their work also revealed that multiple high temperature air inlets into the combustion zone very effectively reduce $N O_{x}$ emissions. Kim et al. (2007) analysed the effect of exhaust gases recirculation and preheating of combustion air on the production of nitrogen oxides. The impact of high temperature combustion air on $N O_{x}$ emissions in combustion of fluid coal has been studied by Rong (2004). A significantly lower formation of nitrogen oxides has been noticed with high-temperature combustion air as compared with normal temperatures. Combustion process modelling and the formation of nitrogen oxides emissions is described by $\mathrm{Xu}$ (2000), who, by means of the numerical simulation, analyzes the combustion process in $350 \mathrm{MWe}$ boilers combusting fluid coal. He also simulates the effect of air flow velocity changes on $N O_{x}$ formation in biomass combusting boilers, originally designed for combusting coal. An increase in the air flow velocity logically leads to temperature reduction in the combustion zone and a small reduction of nitrogen oxides.

In existing boilers, without modernization, it is rather difficult to affect $N O_{x}$ production by some of the above mentioned factors. One possibility is to regulate the amount of combustion air, but this approach represents a significant limitation in the assessment of global issues in controlling $N O_{x}$ production.

The authors of the presented work made an attempt to develop a model which would be based on continuously onsite measurable parameters of combustion. Therefore, the attention was paid, among others, to exhaust gases temperature in their exit from the boiler, which may indicate the quality of combustion processes.

Many of authors further mentioned have tried to develop a mathematical model of the nitrogen oxides formation for various types of combusted fuels. These models have been developed separately for combustion of fossil fuels (Zeldovič et al, 1980), biomass (Dzurenda, 2005), natural gas (Ibler and Karták, 1990) and wooden waste (Klika et all, 2010). Taking into account the complexity of exact description of the nitrogen oxides formation process in combustion of various types of fuel, it is not possible to develop a single generally applicable model describing $N O_{x}$ production in various types of boilers with different types of fuel. Thus, there is a continuous search for new procedures and methods to describe $N O_{x}$ formation process. The dimensional analysis presented in this work can be used as a mathematical model of $N O_{x}$ formation. 


\section{DIMENSIONAL ANALYSIS}

Dimensional analysis is based on a proper selection of parameters affecting the analysed process. Omitting any parameters related to the examined phenomenon may result in inaccurate outcomes because the obtained set of similarity criteria will be incomplete. On the other hand, it may not be a mistake if, in search for mathematical relations with application of dimensional analysis, such parameters are introduced that have no effect on the examined phenomenon, as these are usually eliminated in the course of further search for the similarity criteria.

The characteristic feature of this method is that it operates with the dimensions of parameters which affect the process, and not the parameters themselves, while looking for mathematical relations. Only afterwards results are transformed into the criteria of similarity (dimensionless arguments) $\pi$. The procedure for finding the criteria of similarity for the description of a given phenomenon of the dimensional analysis is quite complicated and may be found, e.g., in the work of Čarnogurská (1998). A short procedure will be shown in the derivation of specific criteria of similarity for a combustion process.

The application of dimensional analysis makes it possible to find a universally valid mathematical dependence between selected relevant operating parameters of a boiler and the formation of nitrogen oxides, but for each type of boiler and fuel, and its quality, it is necessary individually to find $C, m, n$ constants for the model being developed (Eq. (19)), based on the on-line measurements of the operating parameters. They are presented in the following chapter. Any changes in the quality of fuel during combustion (changed calorific value, different humidity), thus also induced changes in the volume of combustion air and its temperature, are directly reflected in the production of $N O_{x}$, in the measured temperature of the exhaust gases, in the measured output of the boiler, etc.

If the method for estimation of $N O_{x}$ employs the dimensional analysis, it is not relevant to identify details of the actual combustion equipment, such as e.g. its design, combustion air distribution system, positions of burners, etc. It is also irrelevant to study what will happen, if during the combustion of fuel also its humidity will change. All of these effects are reflected in the model through measured values of quantities that make up the model itself.

The model makes it possible to determine the production of nitrogen oxides at a given time period, with specific operational parameters and fuel quality, and to compare this production with that under the same on-line measured operating parameters. During the monitored time period (day, week, month) specific values of $N O_{x}$ corresponding to specific operating conditions (e.g., one value per minute) are recorded by the on-line measurement system. Values of the similarity criteria $\pi_{l}$ and $\pi_{2}$, in accordance with the formulas (10) and (11), are specified from the values of operating parameters at a given time. The intercept constant $A$, regression coefficient $B$ and then the constants $C, m, n$ are determined for the formula (19) from the functional dependence of these criteria (14).

\section{DERIVATION OF THE SIMILARITY CRITERIA BASED ON DIMENSIONAL ANALYSIS}

Based on the operator's experience, the following characteristic parameters were selected as the relevant parameters affecting the nitrogen oxides formation in combustion equipment, analysed in this work (a steam boiler with the capacity of $180 \mathrm{t} \cdot \mathrm{h}^{-1}$, TEKO a. s. Košice). This selection made it possible to conduct continual measurements on every kind of equipment. These values are:

- calorific value of the fuel, $Q_{\mathrm{u}}, \mathrm{J} \cdot \mathrm{kg}^{-1}=\mathrm{m}^{2} \cdot \mathrm{s}^{-2}$,

- capacity of the boiler, $P_{k}, \mathrm{~kg} \cdot \mathrm{s}^{-1}$,

- volume of the combustion air, $Q_{\mathrm{vz}}, \mathrm{m}^{3} \cdot \mathrm{s}^{-1}$,

- depression in the boiler, $p_{\mathrm{p}}, \mathrm{Pa}$, 
- volume of nitrogen oxides, $N O_{\mathrm{x}}, \mathrm{kg} \cdot \mathrm{m}^{-3}$,

- temperature of exhaust gases at the exit from the boiler, $T_{\mathrm{sk}}, \mathrm{K}$,

- temperature of the combustion air, $T_{\mathrm{vz}}, \mathrm{K}$.

The combustion temperature plays a significant role in $N O_{x}$ formation. However, its on-line permanent measurements are very difficult. The omission of this parameter in the described model is intentional. The effect of the combustion temperature on the $N O_{x}$ formation, for the given type of boiler, has been monitored only through the relation to the exhaust gases' temperature at the exit from the boiler. It is assumed that there is certain relationship between the combustion temperature and the temperature of exhaust gases at the exit from the boiler.

It is possible, in terms of dimensional analysis application rules, to develop a complete physical formula expressing a relation between these parameters having various dimensions, including the examined $N O_{x}$ formation, in the form:

$$
f\left(Q_{\mathrm{u}}, P_{\mathrm{k}}, Q_{\mathrm{vz}}, p_{\mathrm{p}}, N O_{\mathrm{x}}, T_{\mathrm{sk}}, T_{\mathrm{vz}}\right)=0
$$

Based on a dimensional diversity of individual parameters $V_{i}$, these will be represented by groups, i.e. for the examined similarity criteria $\pi$ the following formula can be applied:

$$
\pi=\prod_{i=1}^{n} V_{i}^{x_{i}}
$$

By detailing parameters $V_{i}$ in the formula (2), the following expression of the formula for calculation of the similarity criteria is obtained:

$$
\pi=Q_{\mathrm{u}}^{x_{1}} \cdot P_{\mathrm{k}}^{x_{2}} \cdot Q_{\mathrm{vz}}^{x_{3}} \cdot p_{\mathrm{p}}^{x_{4}} \cdot N O_{\mathrm{x}}^{x_{5}} \cdot T_{\mathrm{sk}}^{x_{6}} \cdot T_{\mathrm{vz}}^{x_{7}}
$$

Because among the selected parameters $V_{i}$ the temperature dimension occurs twice, the ratio $T_{\mathrm{sk}} / T_{\mathrm{vz}}$ represents the so-called simplex. The measurements carried out in the examined boiler showed that the temperature simplex almost did not change within the range of the measurements of other parameters. Its mean value ranged around the 0.852 level. At such temperature ratio during the boiler operation, the above mentioned physical quantities reached concrete values, which were being continually measured, recorded and utilised in the calculation of individual dimensionless arguments.

The formulation of dimensionless arguments is based on the dimensional matrix $\mathbf{A}$, which has for the fundamental physical quantities $(\mathrm{m}, \mathrm{s}, \mathrm{kg}, \mathrm{K}$ ) of the six selected physical quantities a total of $n=6$ columns and $m=4$ rows. It has the following form:

$$
\begin{array}{c||rrrrrl||}
\multicolumn{1}{c}{} & Q_{\mathrm{u}} & P_{\mathrm{k}} & Q_{\mathrm{vz}} & p_{\mathrm{p}} & N O_{x} & T_{\mathrm{sk}} \\
\mathrm{m} & 2 & 0 & 3 & -1 & -3 & 0 \\
\mathrm{~s} & -2 & -1 & -1 & -2 & 0 & 0 \\
\mathrm{~kg} & 0 & 1 & 0 & 1 & 1 & 0 \\
\mathrm{~K} & 0 & 0 & 0 & 0 & 0 & 1
\end{array}
$$

For the rank of matrix $h=4$ and the number of relevant parameters $n=6$, a total of $i=n-m$, i.e. 2 dimensionless arguments $\pi$ will be created. To obtain them, the dimensional matrix (4) should be divided into two parts, so one represents the square matrix (matrix $\mathbf{A}$ in the Equation (5)) and the other part represents the complementary matrix (the $\mathbf{D}$ matrix in the Equation (5)). A selection of columns for the square matrix from Equation (4) must have a non-zero determinant. Additionally, the selection of unknown parameters $\boldsymbol{x}_{i}$ will be adjusted accordingly. For the matrixes with $\mathbf{A}$ and $\mathbf{D}$ dimensions and vector matrixes of unknown parameters $\mathbf{B}$ and $\mathbf{E}$ the following equation can be applied:

$$
\mathbf{A} \cdot \mathbf{B}=(-1) \cdot \mathbf{D} \cdot \mathbf{E}
$$

By detailing of the Equation (5) the following formula is produced: 


$$
\left\|\begin{array}{rrrr}
2 & 0 & 3 & 0 \\
-2 & -1 & -1 & 0 \\
0 & 1 & 0 & 0 \\
0 & 0 & 0 & 1
\end{array}\right\| \cdot\left\|\begin{array}{l}
x_{1} \\
x_{2} \\
x_{3} \\
x_{6}
\end{array}\right\|=(-1) \cdot\left\|\begin{array}{rr}
-3 & -1 \\
0 & -2 \\
1 & 1 \\
0 & 0
\end{array}\right\| \cdot\left\|\begin{array}{l}
x_{5} \\
x_{4}
\end{array}\right\|
$$

The determinant of matrix $\mathbf{A}$ has the value $\Delta_{\mathbf{A}}=-4$.

The selection of redundant unknown parameters $x_{5}$ and $x_{4}$ from the Equation (6) is executed twice during the calculation, and both selections must be linearly independent. The selection matrix of has the form:

$$
\begin{array}{l|cc} 
& x_{5} & x_{4} \\
\text { 1st sel. } & 1 & 0 \\
\text { 2nd sel. } & 0 & 1
\end{array}
$$

where $\Delta=1$ is its determinant. In this way the condition for the problem solvability is fulfilled.

The solution of Equation (6) with taking into account the conditions stated in Equation (7), leads to a set of linear equations of the following form (8)

$$
\begin{aligned}
2 \cdot x_{1}+3 \cdot x_{3} & =3 \cdot x_{5}+x_{4} \\
-2 \cdot x_{1}-x_{2}-x_{3} & =2 \cdot x_{4} \\
x_{2} & =-x_{5}-x_{4} \\
x_{6} & =0
\end{aligned}
$$

A solution of this set of linear equations gives two independent vectors $\pi_{1}$ and $\pi_{2}$, for which the values $x_{1}$ to $x_{6}$ from Equation (8) can be determined:

$$
\begin{aligned}
& \begin{array}{llllll}
x_{1} & x_{2} & x_{3} & x_{4} & x_{5} & x_{6}
\end{array} \\
& \begin{array}{l|rrrrrr}
\pi_{1} & 0 & -1 & 1 & 0 & 1 & 0 \\
\pi_{2} & -1 & -1 & 1 & 1 & 0 & 0
\end{array}
\end{aligned}
$$

Equation (9) may be given in the form of two complex dimensionless arguments. Taking into account the physical parameters $V_{i}$ and the corresponding values of $x_{i}$, we obtained dimensionless arguments in the form:

$$
\begin{gathered}
\pi_{1}=\frac{Q_{\mathrm{vz}} \cdot N O_{\mathrm{x}}}{P_{\mathrm{k}}} \\
\pi_{2}=\frac{Q_{\mathrm{vz}} \cdot p_{\mathrm{p}}}{Q_{\mathrm{u}} \cdot P_{\mathrm{k}}}
\end{gathered}
$$

Based on the determined dimensionless arguments, the dimensionless form of the function, describing $N O_{x}$ formation in black coal combustion, may be represented in the form:

$$
\psi\left(\pi_{1}, \pi_{2}\right)=0
$$

The dimensionless argument $\pi_{1}$ includes the parameter $N O_{x}$, and therefore this argument may be represented as the function of the argument $\pi_{2}$

$$
\pi_{1}=\varphi\left(\pi_{2}\right)
$$

The form of Function (13) is determined in such a way that for a given $T_{\mathrm{sk}} / T_{\mathrm{vz}}$ ratio the value of argument $\pi_{2}$ is calculated from values of individually measured parameters, and drawn as an 
independent variable. The argument $\pi_{1}$, and therefore also $N O_{x}$, then will be drawn as an dependent variable to the independent variable $\pi_{2}$ of the function.

The actual representation of Equation (13) may be assumed in the form of the power function

$$
\pi_{1}=A \cdot \pi_{2}^{B}
$$

which may be transformed into the equation for a straight line by finding the logarithm:

$$
\log \pi_{1}=\log A+B \cdot \log \pi_{2}
$$

The values of the intercept constant $A$ and the regression coefficient $B$ shall be obtained directly from the developed functional relations utilising Excel spreadsheet program. The actual curve shape of the function $\log \pi_{1}=\varphi\left(\log \pi_{2}\right)$ may be determined on the basis of the measurements of relevant parameters (Table 1), as well as the course of relation between the dimensionless arguments $\pi_{1}, \pi_{2}$ in the logarithmic co-ordinates (Fig. 1). The intercept constant $A$ and the regression coefficient $B$ are also determined directly from Fig. 1 . Their values are $A=0.0117, B=0.2416$. Subsequently from these values constants $C, m, n$ were determined for Equation (19). The table shows a total of 24 values for each measured variable. Each of them represents an average of the obtained parameters during 1 hour of continual measurement of all the parameters with a read-cycle of 1 minute. The whole set of values in Table 1 includes measurements conducted on one day (a total of 1440 measurements). The measurements were carried out by an external company, which provides information about measuring devices used in the measurement protocol - continual analyzers, measurement ranges, uncertainty of measurements, and evaluation time period. For example, for NO volume concentration analyzer, NDIR BINOS - Rosemount, with a range of 0 to $1200 \mathrm{ppm}$, the uncertainty of measurement is $2 \%$, evaluation period is $10 \mathrm{~s}$., etc. In this case the measurements carried out on the boiler were not a part of the warranty measurements.

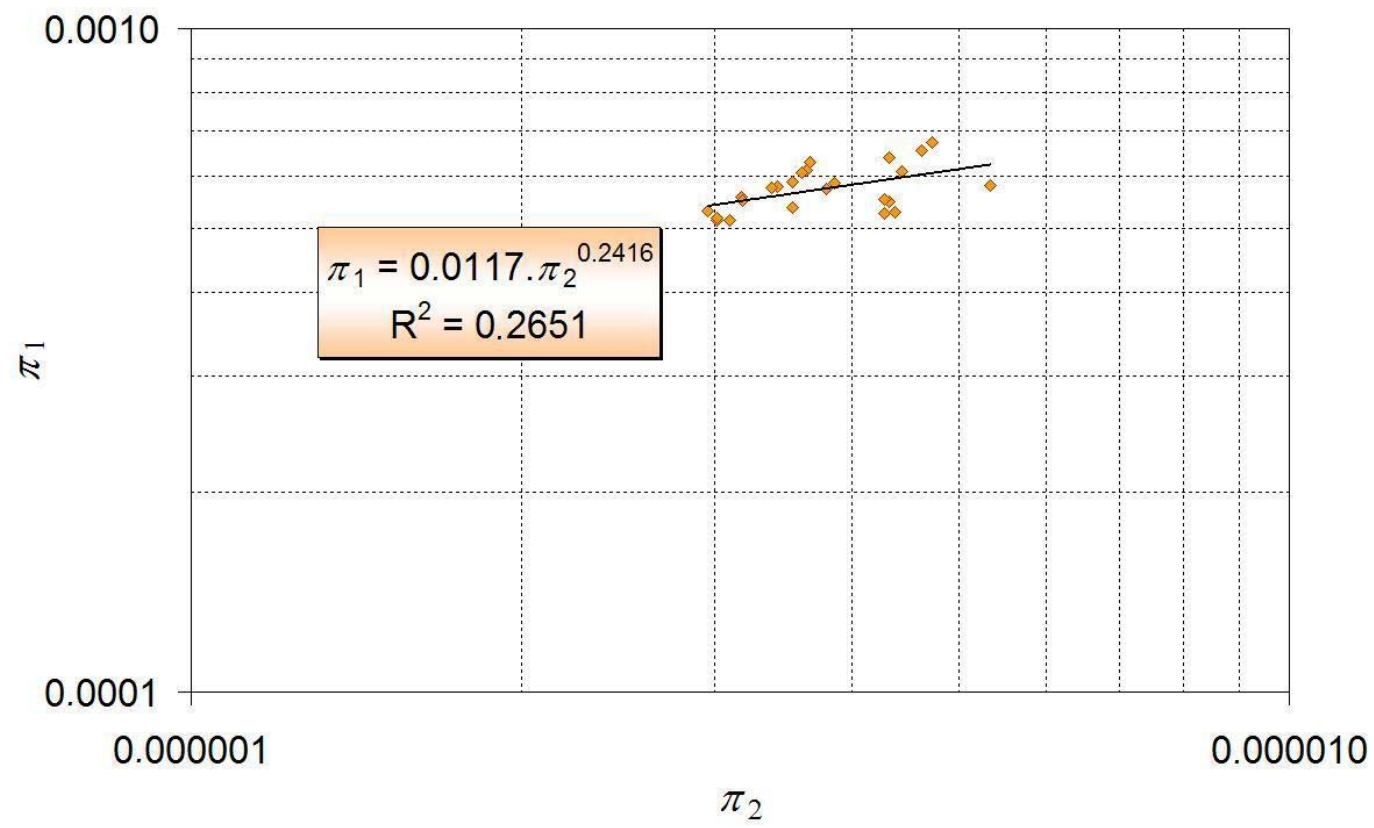

Fig. 1. Dimensionless arguments and regression line represented in the logarithmic co-ordinates 
Table 1. The values of the relevant parameters measured and calculated value of $N O_{\mathrm{x}, \mathrm{cal}}$ according to Equation (19)

\begin{tabular}{|c|c|c|c|c|c|c|c|c|}
\hline $\begin{array}{c}T_{\mathrm{vz}} \\
{[\mathrm{K}]}\end{array}$ & $\begin{array}{c}T_{\mathrm{sk}} \\
{[\mathrm{K}]}\end{array}$ & $\begin{array}{c}Q_{\mathrm{vz}} \\
{\left[\mathrm{m}^{3} \cdot \mathrm{s}^{-1}\right]}\end{array}$ & $\begin{array}{c}P_{\mathrm{k}} \\
{\left[\mathrm{kg} \cdot \mathrm{s}^{-1}\right]}\end{array}$ & $\begin{array}{c}p_{\mathrm{p}} \\
{[\mathrm{Pa}]}\end{array}$ & $\begin{array}{c}Q_{\mathrm{u}} \\
{\left[\mathrm{J} \cdot \mathrm{kg}^{-1}\right]}\end{array}$ & $\begin{array}{c}N O_{\mathrm{x}, \mathrm{meas}} \\
{\left[\mathrm{kg} \cdot \mathrm{m}^{-3}\right]}\end{array}$ & $\begin{array}{c}N O_{\mathrm{x}, \mathrm{cal}} \\
{\left[\mathrm{kg} \cdot \mathrm{m}^{-3}\right]}\end{array}$ & $\begin{array}{c}\text { Deviation } \\
{[\%]}\end{array}$ \\
\hline 520.65 & 443.15 & 61.11 & 50.00 & 110 & 25150000 & 0.000475 & 0.000510 & -7.47 \\
\hline 520.65 & 443.15 & 62.22 & 57.22 & 100 & 25150000 & 0.000505 & 0.000545 & -7.82 \\
\hline 520.65 & 443.15 & 62.22 & 57.78 & 100 & 25150000 & 0.000513 & 0.000548 & -6.83 \\
\hline 520.65 & 443.15 & 62.22 & 57.78 & 100 & 25150000 & 0.000489 & 0.000548 & -12.07 \\
\hline 513.15 & 436.15 & 61.11 & 55.56 & 100 & 25150000 & 0.000481 & 0.000540 & -12.23 \\
\hline 513.15 & 436.15 & 61.67 & 56.94 & 70 & 25150000 & 0.000474 & 0.000501 & -5.71 \\
\hline 513.15 & 436.15 & 61.67 & 56.94 & 70 & 25150000 & 0.000479 & 0.000501 & -4.61 \\
\hline 513.15 & 437.15 & 62.78 & 51.89 & 80 & 25150000 & 0.000483 & 0.000475 & 1.60 \\
\hline 513.15 & 437.15 & 62.78 & 52.78 & 80 & 25150000 & 0.000482 & 0.000482 & -0.06 \\
\hline 513.15 & 443.15 & 61.67 & 54.17 & 70 & 25150000 & 0.000489 & 0.000482 & 1.37 \\
\hline 520.65 & 447.15 & 61.67 & 55.56 & 80 & 25150000 & 0.000530 & 0.000508 & 4.13 \\
\hline 523.15 & 447.15 & 61.67 & 55.56 & 80 & 25150000 & 0.000484 & 0.000508 & -4.98 \\
\hline 523.15 & 435.15 & 64.44 & 54.17 & 70 & 24350000 & 0.000485 & 0.000471 & 2.97 \\
\hline 513.15 & 435.15 & 64.44 & 59.94 & 70 & 24350000 & 0.000479 & 0.000508 & -6.08 \\
\hline 513.15 & 436.15 & 64.44 & 58.33 & 70 & 24350000 & 0.000499 & 0.000498 & 0.29 \\
\hline 513.15 & 438.15 & 60.00 & 58.33 & 70 & 24350000 & 0.000517 & 0.000526 & -1.69 \\
\hline 518.15 & 445.15 & 60.00 & 58.33 & 80 & 24350000 & 0.000560 & 0.000542 & 3.19 \\
\hline 518.15 & 451.15 & 64.44 & 57.78 & 80 & 24350000 & 0.000564 & 0.000510 & 9.49 \\
\hline 520.15 & 433.15 & 64.44 & 58.33 & 80 & 24350000 & 0.000553 & 0.000514 & 7.05 \\
\hline 515.15 & 445.15 & 63.33 & 57.78 & 80 & 24350000 & 0.000554 & 0.000516 & 6.80 \\
\hline 515.15 & 445.15 & 63.33 & 54.17 & 90 & 24350000 & 0.000546 & 0.000507 & 7.15 \\
\hline 515.15 & 438.15 & 63.33 & 50.56 & 90 & 24350000 & 0.000522 & 0.000481 & 7.83 \\
\hline 515.15 & 436.15 & 63.33 & 49.44 & 90 & 24350000 & 0.000525 & 0.000473 & 9.92 \\
\hline 515.15 & 435.15 & 63.33 & 52.78 & 90 & 24350000 & 0.000508 & 0.000496 & 2.29 \\
\hline
\end{tabular}

Based on Equation (14), the formation of nitrogen oxides in the analysed boiler with black coal combustion, may be described, with the model utilising dimensional analysis, by relations between the individual physical parameters in the following form:

$$
\frac{N O_{\mathrm{x}}}{P_{\mathrm{k}}} \cdot Q_{\mathrm{vz}}=A\left(\frac{Q_{\mathrm{vz}} \cdot p_{\mathrm{p}}}{Q_{\mathrm{u}} \cdot P_{\mathrm{k}}}\right)^{B}
$$

The functional relation between $N O_{x}$ formation and the selected parameters expressed in the Equation (16), is as follows

$$
N O_{\mathrm{x}}=A \cdot Q_{\mathrm{vz}}^{(B-1)} \cdot p_{\mathrm{p}}^{B} \cdot Q_{\mathrm{u}}^{-B} \cdot P_{\mathrm{k}}^{(1-B)}, \mathrm{kg} \cdot \mathrm{m}^{-3}
$$

After inserting the calculated values of the regression coefficient and the intercept constant into Equation (17), this equation will have the following form:

$$
N O_{\mathrm{x}}=0,0117 \cdot\left(\frac{P_{\mathrm{k}}}{Q_{\mathrm{vz}}}\right)^{0,7584} \cdot\left(\frac{p_{\mathrm{p}}}{Q_{\mathrm{u}}}\right)^{0,2416}, \mathrm{~kg} \cdot \mathrm{m}^{-3}
$$


After modifications, the general form of the functional relation between $N O_{x}$ and the selected relevant parameters shall be represented by Formula (19)

$$
N O_{x}=C \cdot\left(\frac{P_{\mathrm{k}}}{Q_{\mathrm{vz}}}\right)^{m} \cdot\left(\frac{p_{\mathrm{p}}}{Q_{\mathrm{u}}}\right)^{n}, \mathrm{~kg} \cdot \mathrm{m}^{-3}
$$

where the individual constants are as follows: $C=0.0117, m=0.7584, n=0.2416$.

Formula (19) represents the mathematical model of $N O_{x}$ formation in high-performance boilers of similar design during combustion of fossil fuels, with the same quality as in the boiler examined in this work. Based on the developed model, the values of $N O_{x}$ are calculated from measured individual values of relevant parameters, presented in Table $1-N O_{x, \text { call }}$. The measured and calculated $N O_{x}$ values are shown in Fig. 2.

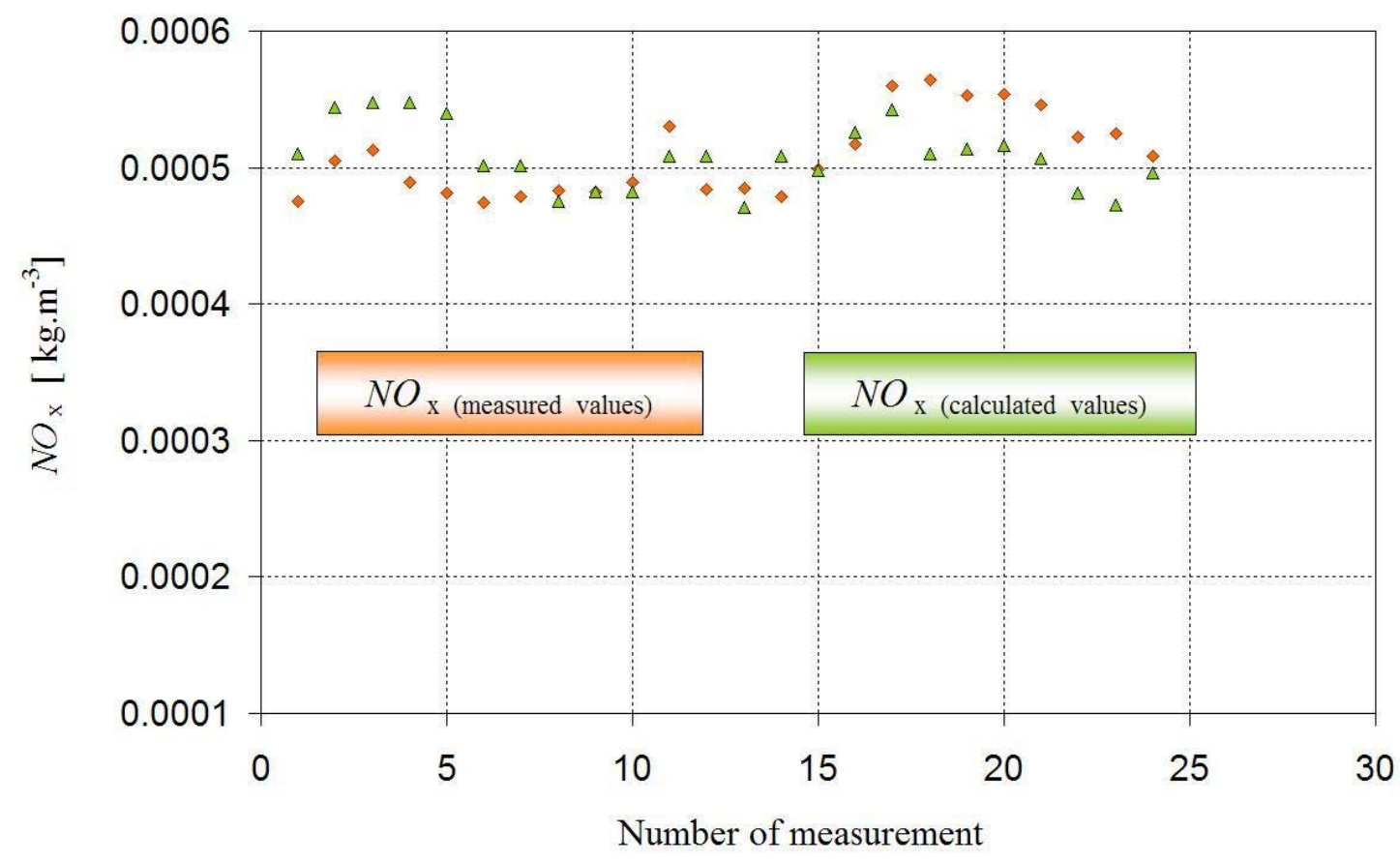

Fig. 2. Measured and calculated values of $N O_{x}$

\section{METHODOLOGY VERIFICATION WITH THE BIOMASS BOILER}

The model of nitrogen oxide formation, presented in Equation (19), was also verified with the boiler VERNER V140 combusting biomass. In the case of dendromass combustion the situation in formation of the $N O_{x}$ is complicated by the fact that nitrogen content in wood and bark varies and depends on the actual ratio between the combusted bark and wood. Model (19), used for calculations of $N O_{x}$ produced in the combustion of wood, includes the correlation between nitrogen contained in wood and bark and nitrogen oxides contained in the exhaust gases only by the means of exhaust gases temperature at the exit from the boiler. It is assumed, as it was already mentioned, that this temperature is directly related to the temperature in the combustion chamber, where continual measurements in field operations are very difficult.

The type of combusted wood and bark, their nitrogen content or the moisture of dendromass, for expression of nitrogen oxides by Equation (19) may not be taken into account directly. The mentioned effects are reflected in the model via measured values of those variables which form the model. The measured nitrogen oxides reflect the quality and nature of combustion process in its complexity. The 
impact of combusted wood and bark or their humidity on the actual production of nitrogen oxides is only reflected by the constants $A, B$ and thus the constants $C, m, n$. The constants $C, m, n$ for a relevant type of combusted dendromass must always be obtained by experiment.

For the purpose of model (19) verification the company VERNER provided data on the measured physical quantities (Table 2). These are average values obtained by continual measurements at two operating stages of the boiler. Two measurements were carried out at the rated output (about $13000 \mathrm{~W}$ ), and one at about half of the rated output. The measurements were carried out by an external contractor (Strojírenský zkušební ústav, s.p. Brno, Czech Republic). The measurement methodology followed the standard ČSN EN 303-5:2000. The measuring instruments used for the measurements, with the relevant uncertainty of measurements are listed in the Measurement Report. For example the HORYBA ENDA - 680P Analyzer used for exhaust gases has the uncertainty $\pm 5 \%$ of the measured value. The measurements on the boiler were the guarantee type of measurements.

Table 2. Measured values of the relevant parameters and $N O_{x}$ values calculated in accordance with Equation (19) for V140 boiler

\begin{tabular}{|c|c|c|c|c|c|c|c|c|}
\hline $\begin{array}{c}P_{\mathrm{k}} \\
{\left[\mathrm{kg} \cdot \mathrm{s}^{-1}\right]}\end{array}$ & $\begin{array}{c}Q_{\mathrm{vz}} \\
{\left[\mathrm{m}^{3} \cdot \mathrm{s}^{-1}\right]}\end{array}$ & $\begin{array}{c}Q_{\mathrm{u}} \\
{\left[\mathrm{J} \cdot \mathrm{kg}^{-1}\right]}\end{array}$ & $\begin{array}{c}T_{\mathrm{sk}} \\
{[\mathrm{K}]}\end{array}$ & $\begin{array}{c}T_{\mathrm{vz}} \\
{[\mathrm{K}]}\end{array}$ & $\begin{array}{c}p_{\mathrm{p}} \\
{[\mathrm{Pa}]}\end{array}$ & $\begin{array}{c}N O_{\mathrm{x}, \mathrm{meas}} \\
{\left[\mathrm{kg} \cdot \mathrm{m}^{-3}\right]}\end{array}$ & $\begin{array}{c}N O_{\mathrm{x}, \mathrm{cal}} \\
{\left[\mathrm{kg} \cdot \mathrm{m}^{-3}\right]}\end{array}$ & $\begin{array}{c}\text { Deviation } \\
{[\%]}\end{array}$ \\
\hline $9.0978 \cdot 10^{-4}$ & 0.0065 & 14520000 & 384.45 & 295.55 & 10 & 0.00021154 & 0.00021052 & 0.48 \\
\hline $9.3182 \cdot 10^{-4}$ & 0.0067 & 14520000 & 386.55 & 297.25 & 10 & 0.00020743 & 0.00020856 & -0.54 \\
\hline $4.7727 \cdot 10^{-4}$ & 0.0038 & 14520000 & 376.25 & 298.15 & 10 & 0.00019306 & 0.00019294 & 0.06 \\
\hline
\end{tabular}

With these mean values the comparison between the measured and calculated values of nitrogen oxides using Equation (19), gives a very good match. For combusted dry beech wood with a calorific value of $15.45 \mathrm{MJ} \cdot \mathrm{kg}^{-1}$ (measurement uncertainty of $0.14 \%$ ), the moisture of $16.88 \%$ (with a measurement uncertainty of $0.03 \%$ ), according to Equation (19), the calculated values are $A=0.007518, B=0.1319$. The subsequently determined values of constants are $C=0.007518, m=1.0, n=0.1319$.

With combustion of other types of wood, with a different calorific value and moisture, during the measurements different values of particular model parameters were obtained. Additionally, different values of dimension-free arguments $\pi_{1}$ and $\pi_{2}$, were also obtained and Equation (19), determining the formation of nitrogen oxides, reflected the changes in the type of combusted fuel, and also the production of nitrogen oxides by new values of the intercept constant $A$, regression coefficient $B$ and constants $C, m$ and $n$.

\section{CONCLUSIONS}

The developed mathematical model demonstrated the possibility to apply dimensional analysis for the description of such complicated phenomenon as combustion process. On the other hand, it is necessary to evaluate in a qualified manner results obtained from the developed model. The results in Table 1 and Table 2 show that the deviation in the determination of nitrogen oxides between direct measurements and the developed model ranges from $-12.23 \%$ to $+9.92 \%$ in a coal fuelled boiler, and from $0.54 \%$ to $+0.48 \%$ in a wood-combusting boiler. The discrepancy between the measured and calculated values according to Equation (19) may be justified by the fact that during the selection of relevant parameters, certainly not all factors, on which the formation of $N O_{x}$ depends in fossil fuels combustion were taken into account. Combustion temperature can be deemed as a significant effect not included in the model.

The difference between calculated and measured results emphasizes the necessity of meeting the basic requirements for using dimensional analysis. Such requirements involve detailed knowledge of 
the physical essence of the examined phenomenon and selection of all the relevant parameters, affecting this phenomenon. As mentioned above, among the relevant parameters combustion temperature along with the temperature of exhaust gases at their exit from the boiler, should also be included. In field operations, however, continual measurements of the temperature are difficult, therefore the inclusion of this variable in the development of a mathematical model was abandoned. The omitting of the combustion temperature among the relevant parameters is undoubtedly a mistake when describing nitrogen oxides formation and this deficiency contributes to the observed variations in determining the production of $N O_{x}$ from the mathematical model according to Equation (19) in both boilers.

Despite the problem in the selection of relevant variables affecting nitrogen oxides formation in the combustion of black coal and wood, it can be said that for a given type of boiler we succeeded in finding a mathematical Equation (19) describing the production of nitrogen oxides, which takes into account the operating parameters. Its disadvantage is the fact that for each type of boiler, type of combusted fuel, and its quality, it is necessary to find individual constants $C, m, n$. This model may be used to control nitrogen oxides emissions at the exit from the boiler.

This paper was elaborated in frame of tasks related to the solution of the project VEGA 1/0006/11, GA ČR 106/07/0938 and KEGA 045-015TUKE-4/2010.

\section{REFERENCES}

Čarnogurská, M., Př́hoda, M., 2011. Application of the dimensional analysis in modeling of phenomena in the area of energy, Košice, Vienala s. r. o., 26-42 (In Slovak).

Čarnogurská, M., 1998. Dimensional analysis and the theory of similarity and modeling in the practice. Košice, Elfa, s. r. o., 1998, 15-24 (In Slovak).

Dzurenda L., 2003. Low-temperature formation of nitrogen oxides in the combustion process of wet wood in fire places heat generators. Acta Mech. Slovaca, 3, 207-212 (In Slovak).

Fan W., Lin Z., Li Y., Li Y., 2010. Effect of temperature on NO release during the combustion of coals with different ranks. Energy Fuels, 24, 1573-1583. DOI:10.1021/ef901198j.

Horbaj P., 2004. Ecological aspects of combustion. TU of Košice, Košice, 39, (In Slovak).

Ibler Z., Karták J., 1990. Model calculations of emissions of $\mathrm{NO}_{\mathrm{x}}$ in the combustion of fossil fuels. Energetika, 40, 9/10, 346-349 (in Czech).

Jandačka J., Malcho M., 2007. Biomass as an energy source. Juraj Štefuñ - GEORG, Žilina, 31-38, (In Slovak).

Kim J. P., Schnell U., Scheffknecht G., Benim A.C., 2007. Numerical modeling of MILD combustion for coal. Prog. Comp. Fluid Dyn., 7, 6, 337-346.

Klika Z., Kasterko R., Bartoňová L., Kolat P., Čech B., 2010. Waste wood combustion and co-combustion with lignite a fluidized - bed power station. Chem. Process Eng., 31, 273-287.

Muzio L.J., Quartucy G.C., 1997. Implementing $\mathrm{NO}_{\mathrm{x}}$ control: Research to application. Prog. Energy Combust. Sci., 23, 233-266. PII: SO360-12\&5(a7)00002-6.

Rédr M., Př́hoda M., 1991. Basics of thermal engineering. SNTL, Prague, Czech Republic, 107, (in Czech).

Rong H., Toshiyuki S., Makoto T., Tetsuya H., Junichi S., 2004. Analysis of low NO emission in high temperature air combustion for pulverized coal. Fuel, 83, 9, 1133-1141.

Xu M., Azevedo, J.L.T., Carvalho, M.G., 2000. Modelling of the combustion process and $\mathrm{NO}_{\mathrm{x}}$ emission in a utility boiler. Fuel, 79, 13, 1611-1619.

Zeldovič J.B., 1947, Oxidation of nitrogen in the combustion. AN, Moskva, 1947, 77-79 (in Russian).

Zeldovič J.B., Barenblatt, G.I., Librovič V.B., Machviladze G.M., 1980. Mathematical theory of combustion and explosion. Nauka, Moscow, 31-35 (in Russian).

Zhu J., Lu Q., Niu T., Song G., Yongjie N., 2009. NO emission on pulverized coal combustion in high temperature air from circulating fluidized bed - an experimental study. Fuel Process. Technol., 90, 5, 664-670. 